\section{ANALISIS FAKTOR - FAKTOR DAN PERHITUNGAN BIAYA DALAM MENENTUKAN HARGA JUAL TIKET. STUDI KASUS PADA PT. EKA SARI LORENA TRANSPORT BOGOR.}

\author{
Muanas dan Ryan Angga Nugraha \\ Program Studi Akuntansi, Sekolah Tinggi Ilmu Ekonomi Kesatuan \\ Bogor, Indonesia \\ Email : lemlit@stiekesatuan.ac.id
}

\begin{abstract}
There are two main factors in deciding ticket price in transportation providers. They are the direct and indirect costs. Other than that, there are also other external factors affecting the ticket price, which are distance, load factor, expected profit and the managerial decision to increase and/or decrease the ticket selling price. All of these components are calculated until finally come up to final ticket price. The research is conducted to analyse the factors influencing the ticket price and to find out how the ticket price is calculated. The result shows that the research object has properly calculating the ticket selling price, but still can not define a break event point. This is important if the company wishes to achieve its objectives, one of which is maximum profit. The goal in calculation of break event point is to determine the uncertain figure by managerial policy on estimated profit, load factor, and final rounding offs.
\end{abstract}

Key words: direct cost, indirect cost, ticket, selling price

\section{PENDAHULUAN}

Bus merupakan alat transportasi yang memegang peran penting di dalam bidang transportasi, teknologi, ekonomi, dan perkembangan di bidang transportasi. Harga tiket bus suatu perusahaan sangatlah berpengaruh dengan jumlah konsumen di Indonesia.

Ada dua faktor utama dalam penentuan harga jual tiket pada perusahaan penyedia jasa transportasi yaitu biaya langsung dan biaya tidak langsung. Di samping itu ada faktor eksternal lain yang ikut pempengaruhi harga tiket misalkan, jarak tempuh, load factor, laba yang diharapkan dan keputusan direktur yang dapat menaikan atau menurunkan harga jual tiket. Semua komponen - komponen tersebut dihitung sampai akhirnya menemukan sebuah hasil akhir untuk harga jual tiket.

\section{MAKSUD DAN TUJUAN}

1. Untuk mengetahui faktor-faktor apa saja yang mempengaruhi penentuan harga tiket.

2. Untuk mengetahui cara perhitungan harga jual tiket.

\section{TINJAUAN PUSTAKA}

Menurut Supriyono $(2000 ; 16)$, Biaya adalah harga perolehan yang dikorbankan atau digunakan dalam rangka memperoleh penghasilan atau revenue yang akan dipakai sebagai pengurang penghasilan. direct cost, indirect cost, ticket, selling price

021

Submitted JANUARI 2016 Accepted: FEBRUARI 2016 
direct cost, indirect cost, ticket, selling price

022
Biaya (Hansen; 2005, 54) didefinisikan sebagai kas atau nilai ekuivalen kas yang dikorbankan untuk mendapatkan barang atau jasa yang diharapkan memberikan manfaat saat ini atau di masa yang akan datang bagi organisasi. Konsep biaya harus jelas agar sebuah perusahaan memiliki tingkat analisis untuk biaya yang jelas dan dapat mempermudah perusahaan tersebut menjalankan usahanya dan mencapai tujuan.

Harga (Price) adalah salah satu unsure dalam bauran pemasaran (Marketing Mix) yang mempunyai peran penting bahkan sangat menentukan keberhasilan suatu kegiatan pemasaran.Tanpa penetapan harga, seorang pemasar mungkin tidak dapat menawarkan produknya kepada calon pelanggan.

Harga jual merupakan jumlah tertentu yang dibayarkan oleh konsumen terhadap barang atau jasa yang diterima. Harga jual tiket adalah nilai moneter yang harus dikeluarkan calon konsumen untuk mendapatkan servis jasa angkutan transportasi ketujuan masing-masing penumpang.Penentuan harga tiket biasa dikenal sebagai Target Price. Target price (Mulyadi, 2001, 84) adalah akumulasi antara biaya target (standar) yang dikeluarkan untuk memproduksi satu unit barang atau jasa dengan target laba yang diharapkan atas unit barang tersebut.

Perhitungan dalam menentukan harga jual tiket yaitu dengan mengelompokan biaya langsungdan biaya tidak langsung. Ada beberapa langkah yang diambil untuk mempermudah manajemen untuk menentukan target price pada perusahaan transportasi bus, yaitu dengan mengelompokan komponen-komponen biaya tersebut.Yaitu dengan menentukan karakter bus, mengelompokan biaya dan menentukan perkiraan laba yang diinginkan.

\section{METODE PENELITIAN}

Metode yang digunakan dalam penelitian ini adalah dengan menggunakan metode deskriptif dimana menjelaskan mengenai variabel-variabel yang diteliti.

\section{HASIL DAN PEMBAHASAN}

Perhitungan harga jual tiket pada perusahaan transportasi cukup rumit dan harus dikaji secara teliti dan hati - hati.Karena bila terjadi kesalahan perhitungan, maka dampaknya sangat buruk.

Tahapan dalam menghitung harga jual tiket adalah sebagai berikut :

1. Menentukan karakteristik bus.

2. Produksi per bus.

3. Biaya per-seat-kilometer.

4. Perhitungan dari load factor.

5. Perhitungan dari laba.

6. Perhitungan Kebijakan Direksi.

7. Perhitungan Jarak tempuh.

Dalam perhitungan harga jual tiket, perusahaan memiliki metode sendiri dalam mendapatkan hasilnya. Ada beberapa langkah dalam mencari harga jual tiket, dari awal menentukan karakteristik bus hingga hasil akhir yaitu harga jual tiket setelah mengkalikan antara tarif perkilometer dengan jarak tempuh. Ada 4 jenis kelas pelayanan pada perusahaan ini, yaitu Super Executive, Executive, VIP AC dan kelas Bisnis AC. Akan tetapi penulis member batasan lingkup hanya pada kelas Super Executive, Executive, dan VIP AC.

Menurut penulis, perhitungan penentuan harga tiket ini sudah benar, akan tetapi disini penulis belum melihat tentang titik impas atau biasa kita sebut break even 
point. Break even point adalah suatu titik dimana peruhasaan di dalam operasinya tidak memperoleh keuntungan dan tidak mendeita kerugian. Pada bagian ini penulis mencoba menjabarkan cara perhitungan break even point dalam perhitungan harga jual tiket.

Diketahui total biaya pada perhitungan harga tiket kelas super executive adalah sebesar Rp 256,58 dengan total 21 kursi. Jadi dengan kata lain, biaya yang dibebankan dalan sekali keberangkatannya yaitu sebesar $\mathrm{Rp}$ 4.606.893,90. pada perhitungan ini perusahaan menetapkan bilangan load faktor sebesar $80 \%$ dengan harga jual tiket Rp 290.000,00. Jadi dapat kita simpulkan break even poin perusahaan ini adalah saat suatu bus berangkat dengan 16 penumpang yang kita dapat setelah perhitungan $\mathrm{Rp} 4.606 .893,90: \operatorname{Rp} 290.000,00=15,89$ atau dibulatkan menjadi 16 penumpang.

Perhitungan break even point ini bertujuan untuk menentukan bilangan tidak pasti yang ditentukan oleh kebijakan manajemen mengenai estimasi laba yang diinginkan, load faktor, dan juga pembulatan akhir yang dilakukan direksi pada saat penentuan harga tiket.

\section{SIMPULAN}

1. Secara garis besar, biaya dibagi menjadi dua kategori umum, yaitu biaya langsung dan biaya tidak langsung.

2. Perhitungan tarif penumpang dilandasi dari perhitungan biaya dan perhitungan non biaya. Perhitungan tarif penumpang tidak bersifat mutlak, ada perubahan disetiap keadaan. Misalkan kenaikan harga BBM. Hasil dari perhitungan tersebut menghasilkan harga tiket pada kelas Super Executive adalah Rp 290.000,00 perpenumpang, pada kelas Execetive adalah sebesar $\mathrm{Rp}$ 250.000,00 perpenumpang dan Rp 175.000,00 pada kelas VIP AC.

\section{DAFTAR PUSTAKA}

Horngren, Charles T., Srikant M. Datar,George Foster.2008.Akuntansi Biaya:Penekanan Majerial : PT. Mancana Jaya Cemerlang, Jakarta.

Carter, William.2009.Akuntansi Biaya, Edisi 14 : Salemba Empat. Jakarta.

Carter, William, Milton F.usry.2006.Akuntansi Biaya:Edisi13:Salemba Empat, Jakarta.

Witjaksono, Armanto.2006.Akuntansi Biaya :Graha Ilmu, Yogyakarta.

Bustami,Bastian.2009.Akuntansi Biaya:Mitra Wacana Media, Jakarta.

Bustami, Bastian, Nurlela.2006.Akuntansi Biaya:Teori dan Aplikasi: Graha Ilmu, Yogyakarta.

Fred, R David.2004.Manajemen Strategi:SalembaEmpat, Jakarta.

Simon, Schuster 2001 Akuntansi :Salembaempat, Jakarta.

Horngren, Charles 2009 Akuntansi.:Mancana Jaya Cemerlang, Jakarta.

Floyd A. Beams, John A Brozovsky.2005 AkuntansiBiaya :Gramedia, Jakarta.

Mulyadi. 2001. Sistem Akuntansi. Universitas Gajah Mada: Salemba Empat, Jakarta.

Hansen, Mowen 2009.Managerial AccountingEdisi8 :SalembaEmpat, Jakarta.

Carter, William K. 2009. AkuntansiBiaya:SalembaEmpat, Jakarta.

Wikipedia 2012.PengertianAkuntansiBiayaTersedia online di alamat :http://id.wikipedia.org/wiki/Akuntansi_biaya (diakses Mei 2012)

JurnalManajemen 2009. BahanKuliahManajement. Tersedia online di alamat :http://jurnal-sdm.blogspot.com/2009/03/pengertian-dan-penggolonganbiaya.html(diakses Mei 2012)

Wawan\&Junaidi 2010.Penggolonganbiaya.Tersedia online di alamat :http://wawanjunaidi.blogspot.com/2010/11/penggolongan-biaya.html(diakses Mei 2012) direct cost, indirect cost, ticket, selling price 